Check for updates

Cite this: RSC Adv., 2017, 7, 19833

Received 26th January 2017

Accepted 22nd March 2017

DOI: 10.1039/c7ra01169e

rsc.li/rsc-advances

\section{Effects of alkali-oxygen oxidation temperature on the structures and combustion properties of Shengli lignite}

\author{
Dandan Wang, (D) Runxia He, ${ }^{*}$ Bin Wang, Huacong Zhou, Yinmin Song, Keduan Zhi, \\ Jiaming Chen, $\mathrm{Na} \mathrm{Li}$, Yanpeng Ban and Quansheng Liu*
}

Spontaneous combustion has become a critical limiting factor for the safe and efficient utilization of low rank coals. In this work, the alkali-oxygen oxidation (AOO) of Chinese Shengli lignite was conducted to inhibit the spontaneous combustion tendency, and the influences of $A O O$ on the structures and combustion properties were investigated. The structures of $\mathrm{AOO}$ treated lignite under different conditions were characterized by XRD, Raman, XPS and FTIR. The combustion characteristics of the samples were investigated by thermogravimetric analysis and fixed bed combustion. The results revealed that the temperature of $\mathrm{AOO}$ treatment had significant influence on the crystallite structures and combustion characteristics of Shengli lignite. After the AOO pretreatment, the benzene ring skeleton structures in lignite had no obvious changes, but the amounts of aliphatic side chains on the aromatic nucleus decreased. Compared with raw lignite, the degree of order and ignition temperature increased after $\mathrm{AOO}$ treatment, especially when the $\mathrm{AOO}$ temperature was $150-200{ }^{\circ} \mathrm{C}$. The ignition temperatures moved from $310{ }^{\circ} \mathrm{C}$ for raw lignite to $740-760{ }^{\circ} \mathrm{C}$ for the samples treated by $\mathrm{AOO}$ at $150-200{ }^{\circ} \mathrm{C}$. On further increasing the $\mathrm{AOO}$ temperatures to $250-300{ }^{\circ} \mathrm{C}$, the ignition temperature of the samples decreased to $410-440{ }^{\circ} \mathrm{C}$. In conclusion, AOO pretreatment under suitable conditions is an efficient way to inhibit the spontaneous combustion tendency of low rank lignite, and it is believed that the results in this work are meaningful for the safe transportation and efficient utilization process of lignite in industry.

\section{Introduction}

World energy consumption increases constantly along with economic development, and coal will remain the primary energy source for a long time. ${ }^{\mathbf{1 , 2}}$ Clean and efficient utilization of coal is an important issue considering both environmental protection and the sustainable development of human society. ${ }^{3-5}$ Coal is the primary energy source in China, and lowrank coals account for a large proportion of this energy source. ${ }^{6}$ Therefore, the effective utilization of low-rank coals is crucial for sustainable development not only in China but also global areas. Lignite, as a representative of the low rank coals, is an important carbon resource around many areas in the world. ${ }^{7}$ Taking Shengli coalfield in Inner Mongolia, China as an example, the reserve of lignite is up to 24.2 billion tons. Therefore, the clean, efficient and safe utilization of lignite is of great significance for the conversion of coal resources and energy supply.

College of Chemical Engineering, Inner Mongolia University of Technology, Inner Mongolia Key Laboratory of High-Value Functional Utilization of Low Rank Carbon Resources, Huhhot 010051, Inner Mongolia, China.E-mail: 1054260076@qq.com; liuqs@imut.edu.cn; Tel: +86 13664742350; +86 13354899678
Lignite has a complex structure and consists mainly of threedimensional macromolecular networks, various relatively small organic molecules, and inorganic materials. ${ }^{7,8}$ The contents of volatiles and oxygen-containing chemical groups are much higher compared with those of the high rank coals. ${ }^{9-11}$ These structure features make the lignite suffer several defects during utilization, including high content of water and volatiles, low calorific value, the lower ignition temperature, and more prone to spontaneous combustion in air. ${ }^{12}$ These disadvantages limit the utilization of lignite to some extent. During the industrial process, the reaction of lignite with oxygen may result in selfheating and subsequent spontaneous combustion in coalmines and stock piles, leading to serious safety problems and property losses. ${ }^{13}$ Based on this background, studies on the inhibition of the spontaneous combustion of lignite becomes extremely important. Various factors can influence the stability of lignite in air. It was reported that the side chains on the aromatic structures, the bridge bonds, and the low molecular weight organic components in coal structures have mediate to high chemical reactivity. ${ }^{\mathbf{1 4 , 1 5}}$ The unique porous structures of the lignite also make it highly reactive and prone to be oxidized at the low temperatures and/or even spontaneously combustion. Shengli lignite, a typical low-rank coal in Inner Mongolia, China, has a high chemical reactivity due to the high contents of 
oxygen-containing groups in. ${ }^{\mathbf{1 4}}$ Therefore, the inherent composition and structure characteristics of lignite are the main reasons leading to spontaneous combustion.

Low temperature oxidation is the major source of the heat leading to spontaneous combustion of lignite. In order to inhibit the low temperature oxidation and reduce the spontaneous combustion tendency, various work have been reported. ${ }^{16-18}$ Alkali treatment is one of the effective means to suppress spontaneous combustion, which can reduce the contents of organic matters in coal, especially oxygen functional group. Wang et al. ${ }^{17}$ reported that coal oxidation at low temperatures (i.e. below $100{ }^{\circ} \mathrm{C}$ ) was a complicated process and involved four processes, oxygen transport to the surfaces of coal particles, chemical interaction between coal and $\mathrm{O}_{2}$, release of heat, and emission of gaseous products. Mukherjee et al. ${ }^{19}$ found that the increase of alkali concentration and treatment time had negative effects on ash reduction due to formation and accumulation of insoluble sodium aluminosilicate. Nasir et al. ${ }^{20}$ found that the alkali treatment could remove minerals or oxygen containing functional groups. Wijaya et al. ${ }^{21}$ found that silicon aluminum salts in coal transformed into hydrosilicate and aluminosilicate composites after the alkali treatment. Liu et $a .^{22}$ noticed that the ignition temperature, activation energy of lignite were changed by alkali treatment. After treatment with $\mathrm{NaOH}$ solutions with different concentrations, the combustion temperature of coal samples moved to high temperature zone. Feng et al. ${ }^{23}$ indicated that at low alkali concentrations, $\mathrm{NaOH}$ reacted primarily with the acidic functional groups in lignite samples, and the changes in pore volume and adsorption water contents were not obvious. Çulfaz et al. ${ }^{24}$ found that the alkali treatment could remove a lot of $\mathrm{SiO}_{2}$ and $\mathrm{CaO}$ in Turkey's lowash lignite, but it could remove few $\mathrm{Fe}_{2} \mathrm{O}_{3}$ and $\mathrm{Na}_{2} \mathrm{O}$.

Alkali-oxygen oxidation (AOO) of coals to produce the highvalue benzene poly carboxylic acids (BPCAs) is a potential substitute for the petroleum route in the future. There are also some researches on the AOO of lignite for obtaining the valuable benzene carboxylic acids raw materials. ${ }^{25-27}$ Wang et al. ${ }^{28}$ have reported that the high-temperature operation can effectively improve the economy and efficiency of the BPCAs production process from AOO of bituminous coal. According to the above literature, the extraction rate of BPCAs from lignite is only about $20 \%,{ }^{25,27}$ indicating that most of the organic carbon sources were still remained in the solid residues. However, fewer attentions are paid onto the solid residues, which may lead to a waste of resources and pollution of the environment. In fact, there are many valuable components in the solid residues, and it is a potential carbon resource after the extraction of organic matters with low molecular weight via AOO. Thus, exploring the effect of the AOO process on the microcrystalline structure and reaction properties of the residues is a very important issue for the utilization of the solid residue and the understanding of the inhibition on the spontaneous combustion of lignite. At the same time, studying the structure and property change after the AOO is beneficial for broadening the applications of lignite and improving the utilization efficiency.

In this work, we introduce the AOO approach into the pretreatment of lignite, in order to reduce the spontaneous combustion tendency. The Shengli lignite in Chinese Inner Mongolia was chosen as the main research object, and different experimental temperatures during AOO process was systematically carried out. The structures of Shengli lignite treated with AOO were studied by the XRD, Raman, FTIR and XPS characterization techniques, and the combustion reaction performance of the samples were analyzed on the fixed bed and thermogravimetric instrument.

\section{Experimental section}

\subsection{Sample preparation}

The lignite was sampled from Shengli coalfield in Inner Mongolia, China. The lignite was crushed and ground to fine powder with average sizes of $150-180 \mu \mathrm{m}$, followed by drying at $105{ }^{\circ} \mathrm{C}$ for $4 \mathrm{~h}$ for these experiments, and the coal samples was denoted as SL-Raw. The 150-180 $\mu \mathrm{m}$ SL-Raw coal (20 g) was added to reagent-grade aqueous solution of $\mathrm{NaOH}\left(0.5 \mathrm{~mol} \mathrm{~L}^{-1}, 200 \mathrm{~mL}\right)$ with stirring for $3 \mathrm{~h}$ at room temperature. The resulting slurry was filtered and rinsed continuously with deionized water until the $\mathrm{pH}$ of the supernatant was around 8. The obtained solid was dried under $105^{\circ} \mathrm{C}$ for $4 \mathrm{~h}$, and the sample was denoted as SLRT. For the AOO reaction, typically, $20 \mathrm{~g}$ coal sample, $4 \mathrm{~g}$ sodium hydroxide and $200 \mathrm{~mL}$ distilled water were loaded in the reactor, and then oxygen was charged into the reactor with initial pressures of $0.6 \mathrm{MPa}$. And then the reactor was heated by $10{ }^{\circ} \mathrm{C}$ $\min ^{-1}$ to a desired reaction temperature. The reaction mixtures were maintained for $1 \mathrm{~h}$ at constant stirring speed of $300 \mathrm{rpm}$. Then the reaction system was cooled to room temperature. The resulting slurry was filtered and washed continuously with deionized water until the $\mathrm{pH}$ of the supernatant was around 8 . The residue was dried in vacuum at $105^{\circ} \mathrm{C}$ for $4 \mathrm{~h}$. The samples treated by $\mathrm{AOO}$ at the temperatures of $150{ }^{\circ} \mathrm{C}, 200{ }^{\circ} \mathrm{C}, 250{ }^{\circ} \mathrm{C}$ and $300{ }^{\circ} \mathrm{C}$ were denoted as SL-150, SL-200, SL-250 and SL-300, respectively. The proximate and ultimate analyses of the samples are listed in Table 1. Compared to the SL-Raw, the moisture and ash content of coal samples was increased by AOO treatment. The content of volatiles increased slightly for AOO samples at room temperature. When the AOO temperature increased, the content of volatiles decreased. And with the increase of AOO temperatures, the extent of the reduction was increased.

Table 1 Proximate and ultimate analysis of the coal samples ${ }^{a}$

\begin{tabular}{|c|c|c|c|c|c|c|c|c|}
\hline \multirow[b]{2}{*}{ Samples } & \multicolumn{4}{|c|}{ Proximate analysis/\% } & \multicolumn{4}{|c|}{ Ultimate analysis/\% } \\
\hline & $M_{\text {ad }}$ & $A_{\text {ad }}$ & $V_{\text {ad }}$ & $\mathrm{Fc}_{\mathrm{ad}}$ & $\mathrm{C}$ & $\mathrm{H}$ & S & $\mathrm{N} \& \mathrm{O}$ \\
\hline SL-Raw & 3.21 & 12.41 & 37.92 & 46.46 & 57.60 & 3.53 & 1.51 & 24.93 \\
\hline SL-RT & 4.82 & 15.24 & 45.97 & 33.97 & 52.95 & 3.44 & 0.62 & 28.59 \\
\hline SL-150 & 5.98 & 19.31 & 41.58 & 33.13 & 50.28 & 3.20 & 0.42 & 29.00 \\
\hline SL-200 & 3.41 & 14.61 & 36.95 & 45.03 & 43.33 & 2.75 & 0.64 & 36.55 \\
\hline SL-250 & 5.38 & 17.11 & 33.61 & 43.90 & 58.96 & 3.64 & 0.76 & 36.63 \\
\hline SL-300 & 6.81 & 16.73 & 33.83 & 42.63 & 53.54 & 3.23 & 0.77 & 42.45 \\
\hline
\end{tabular}

${ }^{a}$ Note: M - moisture, A - ash, V - volatile and Fc - fixed carbon; ad - air dried. 


\subsection{Analysis of structural properties}

XRD was performed on Germany D8 Advance X-ray Diffraction diffractometer equipped with monochromator and $\mathrm{CuK} \alpha$ radiation $(40 \mathrm{kV}, 40 \mathrm{~mA})$. Powdered samples were scanned from $5^{\circ}$ to $80^{\circ}$ in $2 \theta$ range and scanning speed of $2^{\circ} \mathrm{min}^{-1}$.

The morphology and sodium content of lignite samples was observed using the SEM (model S-3400N) equipped with an energy-dispersive spectrometry (EDS) detector.

Raman spectra were recorded using Renishaw ${ }^{\circledR}$ inVia microscope Raman spectrometer with Nd-YAG laser source $(532 \mathrm{~nm})$. The laser power at the sample surface was controlled at $5 \mathrm{~mW}$. The spectra were recorded in the range of 500 to $3500 \mathrm{~cm}^{-1}$.

The FT-IR spectra of the samples were recorded at the range of $4000-500 \mathrm{~cm}^{-1}$ on Nicolet company infrared spectrometer NEXUS 6700 using the $\mathrm{KBr}$ pellet technique. The total number of scans were 50 with the resolution of $4 \mathrm{~cm}^{-1}$.

$\mathrm{X}$-ray photoelectron spectra were recorded in a Perkin Elmer PHI 5400 XPS ESCA system spectrometer with an Al-K $\alpha$ X-ray exciting source and operated at $200 \mathrm{~W}$. The calibration was carried out based on the main C1s peak at $284.6 \mathrm{eV} \cdot{ }^{29-31}$ Data analysis is conducted on the XPS software (PEAK4.1).

\subsection{Combustion properties and thermogravimetric analysis}

The combustion experiment was carried out on a fixed bed. The schematic diagram of the experimental device is shown in Fig. 1. The experiment was performed as follows: lignite sample (50 $\mathrm{mg}$ ) was doped in the quartz tube reactor. The air flow rate during the experiment was maintained at $30 \mathrm{~mL} \mathrm{~min}^{-1}$ and the temperature was increased from 20 to $900{ }^{\circ} \mathrm{C}$ at a heating rate of $2{ }^{\circ} \mathrm{C} \min ^{-1}$. Gas chromatography (SP-6800 A) analysis was used to detect the generation of released gas.

Thermal Gravimetric Analyzer (TGA) was performed using a Diamond 6300 TG/DTA analyzer. The experiment was performed as follows: lignite sample (15-20 mg) was placed at the bottom of an alumina crucible. The temperature was increased from 20 to $950{ }^{\circ} \mathrm{C}$ at a heating rate of $10^{\circ} \mathrm{C} \mathrm{min}{ }^{-1}$, and the air flow rate during the experiment was maintained at $100 \mathrm{~mL} \min ^{-1}$.

\section{Results and discussion}

\subsection{X-ray diffraction}

$\mathrm{XRD}$ is an important tool to analyze the crystal structure and has been widely used to investigate the physical structure of amorphous materials. Fig. 2 shows the X-ray diffraction patterns of the coal samples and the fitting curves of SL-Raw. The profiles of samples exhibited high background intensity, indicating that the coal contains a proportion of highly disordered materials in the form of amorphous carbon. The presence of the 002 peak at $20-30^{\circ}$ was due to the spatial arrangement of the aromatic ring carbon network layer and the distance between the aromatic ring layers. ${ }^{32}$ The strong peak shape of the $\gamma$ band could be attributed to the saturated structures of lipid and alicyclic chains, which illustrated the presence of the rich alicyclic structures in coal. The 100 peak at $43-45^{\circ}$ is attributed to the condensation degree of the aromatic ring and the size of the aromatic carbon network layer. ${ }^{33}$ Origin-lab 8.5 software was used for "Gauss fitting method" fitting of the XRD patterns in the $2 \theta$ region of $5-70^{\circ}$ (Fig. $2(\mathrm{~b})$ ). According to the Blagg and Scherrer equation, the microcrystal structure parameters of coal samples, ${ }^{34-37}$ including the interlayer space $\left(d_{002}\right)$, the lateral size (La), the stacking height (Lc) and the degree of coalification $(P)$, could be calculated. The peak positions, intensity, area and full width at half maxima (FWHM) obtained after curve-fitting of the $(\gamma),(002)$ and (100) bands, and the calculated structural parameters for all the samples were listed in Table 2. It was shown that the interlayer spacing of each coal sample was greater than that of the pure graphite $(0.336-0.337 \mathrm{~nm}),{ }^{35}$ indicating that the crystallinity of the coal samples are lower than the pure graphite. The stack thickness (Lc), aromatic layer size (La), number of aromatic layer $(N)$ and the degree of coalification $(P)$ increased due to AOO treatment. However, the interlayer spacing $\left(d_{002}\right)$ after AOO was lower than that of SLRaw. Thus, these results indicated that AOO treatment destroyed the degree of crystalline order of the coal. When AOO temperature was $150-200{ }^{\circ} \mathrm{C}$, the degree of coalification $(P)$ came to the maximal value. It was shown that the crystal structure became more and more regular during the oxygen oxidation process.

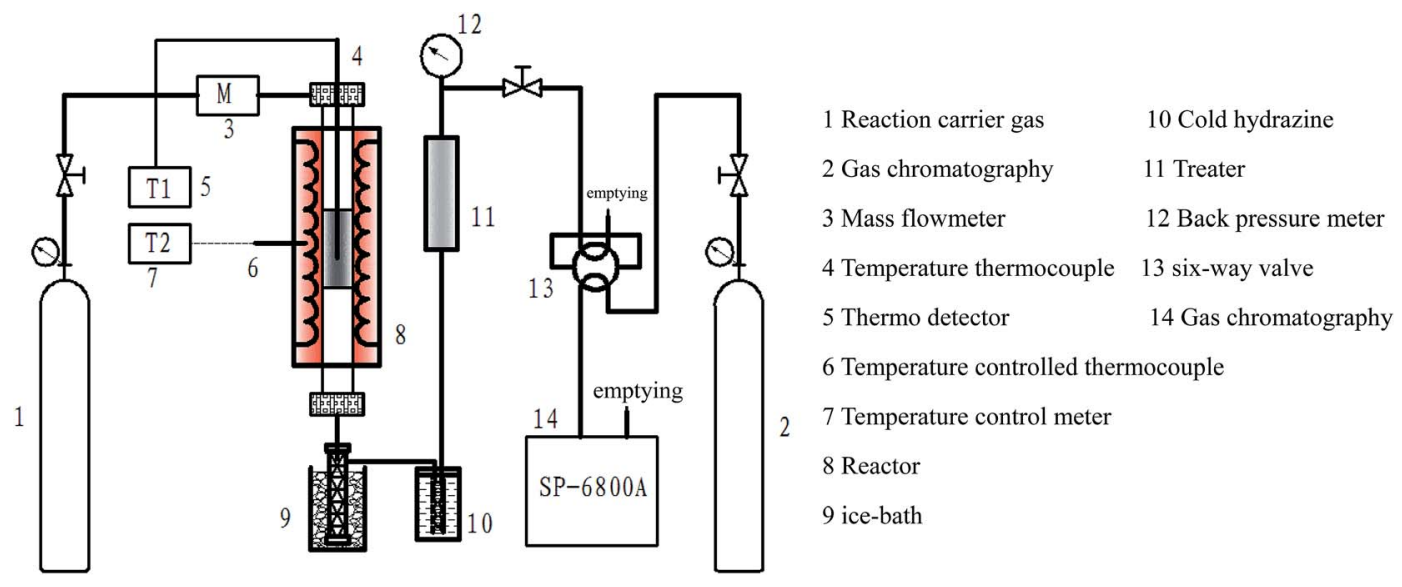

Fig. 1 Schematic diagram of the experimental installation. 


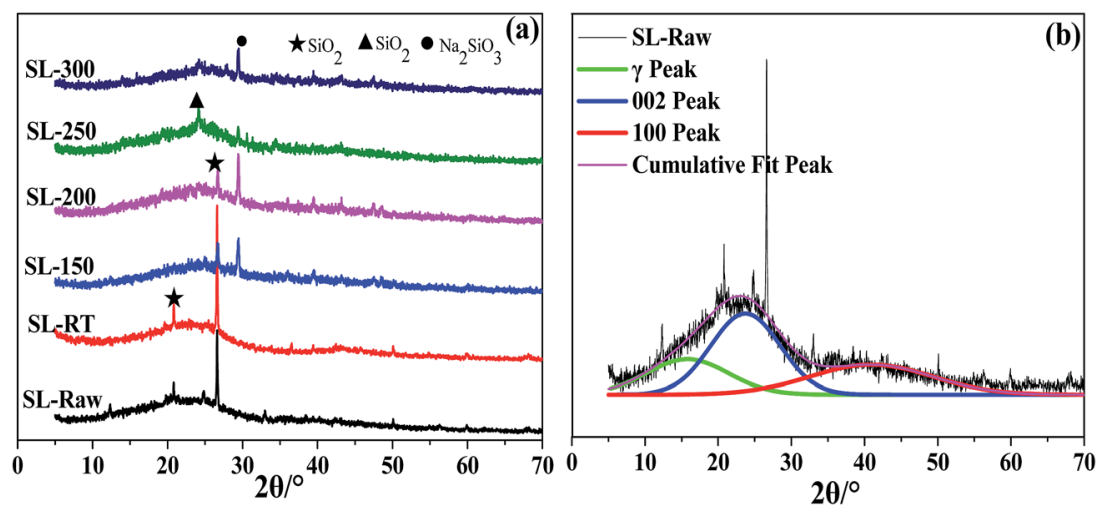

Fig. 2 XRD patterns of the coal samples and the fitting curves of SL-Raw. (a) Experimental; (b) fitting.

Table 2 Crystalline structure parameters of the coal samples

\begin{tabular}{llllll}
\hline Samples & $2 \theta(002) /{ }^{\circ}$ & $d_{002} / \mathrm{nm}$ & Lc/nm & La/nm & $P$ \\
\hline SL-Raw & 22.74 & 0.3745 & 0.7219 & 0.8851 & 0.3704 \\
SL-RT & 24.10 & 0.3690 & 0.7593 & 0.9377 & 0.4589 \\
SL-150 & 25.99 & 0.3425 & 0.8684 & 1.0456 & 0.8857 \\
SL-200 & 26.11 & 0.3410 & 0.8919 & 1.0548 & 0.9098 \\
SL-250 & 24.89 & 0.3574 & 0.8071 & 0.9590 & 0.6457 \\
SL-300 & 25.24 & 0.3525 & 0.8356 & 0.9657 & 0.7246 \\
& & & & & \\
\hline
\end{tabular}

In addition, Fig. 2 shows the XRD pattern for the AOO coal samples at room temperature had an obvious peak of $\mathrm{SiO}_{2}$ with the highest intense at $2 \theta=26.56^{\circ}$. After AOO treatment at 150 $200{ }^{\circ} \mathrm{C}$, the intensity of the $\mathrm{SiO}_{2}$ diffraction peak was greatly weakened, and a strong $\mathrm{Na}_{2} \mathrm{SiO}_{3}$ diffraction peak appeared. When the AOO treatment temperature increased to $250-300{ }^{\circ} \mathrm{C}$, the $\mathrm{Na}_{2} \mathrm{SiO}_{3}$ diffraction peak decreased, and $2 \theta=24.23^{\circ}$ (JCPDS 82-1574) of $\mathrm{SiO}_{2}$ generated. SEM-EDS analysis results showed that different amounts of sodium existed on the surface of all AOO samples under the temperature range studied, with the lowest content for the AOO samples treated at $250-300{ }^{\circ} \mathrm{C}$. XRD patterns indicated that the sodium element existed in the form of sodium silicate for the AOO samples. These results indicated that the degree of crystalline order of the coal samples was increased after AOO at different temperatures, especially at 150 and $200{ }^{\circ} \mathrm{C}$. It was speculated that the increase of the components with lower reactivity in coal samples leading to the increase of the degree of crystalline order of the coal samples.

\subsection{Raman characterization}

Raman spectroscopy analysis was performed in order to improve the understanding of the microcrystalline structure of coal samples treated by AOO at different temperatures. Fig. 3 showed that the Raman spectra of the coal samples and the fitting curves of SL-Raw. All the curves exhibited two broad and overlapping peaks with maximal intensity at $1340-1380 \mathrm{~cm}^{-1}$ and $1580-1600 \mathrm{~cm}^{-1}$ which corresponded to the D and $\mathrm{G}$ bands of disordered graphite, respectively. ${ }^{38} \mathrm{D}$ peak and $\mathrm{G}$ peak represented the defect peak in coal (usually caused by the defects in the plane and the vibration of the impurity atoms) and the large aromatic ring structure in coal. Raman spectra in the range between $800-1800 \mathrm{~cm}^{-1}$ were curve-fitted with the Origin 8.5 software using 9 Gaussian bands. ${ }^{39,40}$ An example of Raman spectral curve fitting was shown in Fig. 3(b). The related results were given in Table 3 .

The $I_{\mathrm{D}} / I_{\mathrm{G}}$ ratio represents the surface defect degree (disordered carbon at the edge part) of the coal graphite. ${ }^{\mathbf{4 1 - 4 3}} \mathrm{A}$ decrease in the $I_{\mathrm{D}} / I_{\mathrm{G}}$ ratio normally occur with the increase of the degree of graphitization. For the chars studied, the $I_{\mathrm{D}} / I_{\mathrm{G}}$ ratios decreased after the AOO treatment at different temperatures. Especially, the $I_{\mathrm{D}} / I_{\mathrm{G}}$ value came to the lowest value when the temperature of AOO was in the range of $150-200{ }^{\circ} \mathrm{C}$. This result indicated that the defect level in the coal samples treated by AOO at different temperatures decreased, and the proportion of the lattice defect structure also decreased. When the temperature of AOO increased to $250-300{ }^{\circ} \mathrm{C}$, the degree of defect of coal samples increased, which was consistent with the results of XRD characterization. The $\mathrm{S}$ bands represented $\mathrm{sp}^{3}$-rich structures such as alkyl-aryl C-C structures and methyl carbon dangling to an aromatic ring. ${ }^{44}$ The $I_{\mathrm{S}} / I_{\mathrm{G}}$ ratio decreased after the AOO treatment at different temperatures. After the treatment of AOO, the contents of the side chains on the aromatic nucleus decreased, and it came to the lowest value when the temperature of AOO fell in the range of $150-200{ }^{\circ} \mathrm{C}$. The higher value of $I_{\mathrm{GL}} / I_{\mathrm{G}}$ ratio indicated higher content of carbonyl groups. After the treatment of AOO, the content of carbonyl groups decreased, indicating that certain substances containing - $\mathrm{COOH}$ groups were exfoliated into the solution. The $\mathrm{G}_{\mathrm{R}}, \mathrm{V}_{\mathrm{L}}$ and $\mathrm{V}_{\mathrm{R}}$ bands, i.e. the 'overlap' between the $\mathrm{G}$ and $\mathrm{D}$ bands, represented the typical structures in amorphous carbon materials, particularly the relatively small aromatic ring systems having 3-5 benzene rings. The higher value of $I_{\mathrm{D}} / I_{\left(\mathrm{G}_{\mathrm{R}}+\mathrm{V}_{\mathrm{R}}+\mathrm{V}_{\mathrm{L}}\right)}$ ratio indicated the lower content of $-\mathrm{CH}_{3}$ and $-\mathrm{CH}_{2}$ connected directly with benzene rings. The data in Table 3 showed that the content of $-\mathrm{CH}_{3}$ and $-\mathrm{CH}_{2}$ linked with aromatic rings was reduced by the AOO treatment. These results showed that the number of aliphatic side chains on aromatic nuclear and the contents of carbonyl groups decreased, and the degree of crystalline order of the coal samples increased after AOO at different temperatures, and the contents of the components with high reactivity decreased, which was more obvious for the samples of SL-150 and SL-200. 

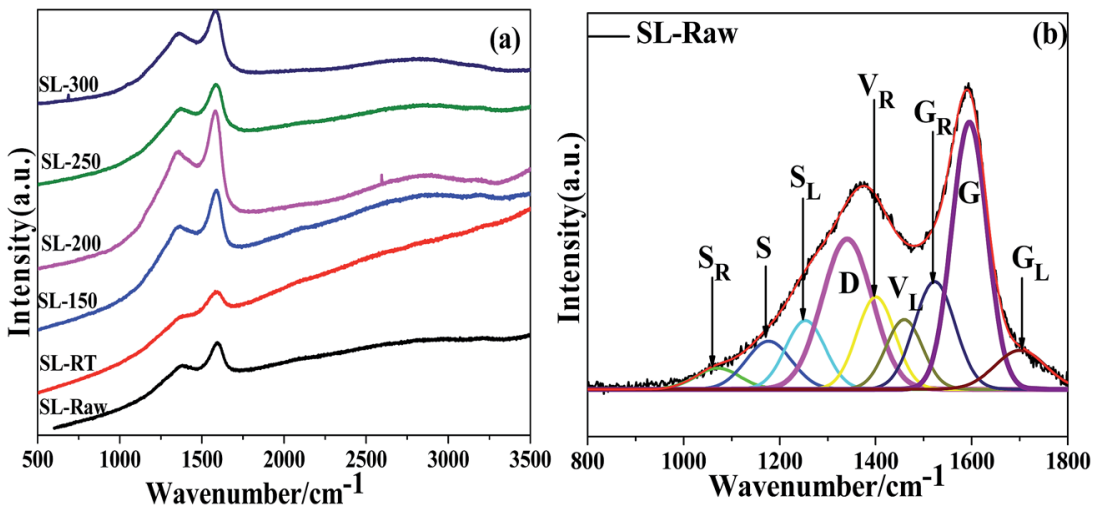

Fig. 3 Raman spectra of the coal samples and the fitting curves of SL-Raw (a) experimental; (b) fitting.

Table 3 Raman spectroscopic parameter of the coal samples

\begin{tabular}{lcccl}
\hline Samples & $I_{\mathrm{D}} / I_{\mathrm{G}}$ & $I_{\mathrm{S}} / I_{\mathrm{G}}$ & $I_{\mathrm{GL}} / I_{\mathrm{G}}$ & $I_{\mathrm{D}} / I_{\left(\mathrm{G}_{\mathrm{R}}+\mathrm{V}_{\mathrm{R}}+\mathrm{V}_{\mathrm{L}}\right)}$ \\
\hline SL-Raw & 0.8028 & 0.2322 & 0.2100 & 0.7210 \\
SL-RT & 0.7942 & 0.2204 & 0.1632 & 0.8017 \\
SL-150 & 0.7418 & 0.1753 & 0.1073 & 0.8352 \\
SL-200 & 0.7351 & 0.1625 & 0.1068 & 0.8277 \\
SL-250 & 0.7618 & 0.1990 & 0.1123 & 0.8193 \\
SL-300 & 0.7669 & 0.1912 & 0.1173 & 0.8102 \\
& & & & \\
\hline
\end{tabular}

\section{$3.3 \quad$ FT-IR spectra}

The change of the functional groups in the process of AOO treatment can be detected by the change of infrared spectrum. Fig. 4 shows the FTIR spectrum of SL-Raw coal and AOO treated coal samples at different temperatures. The results showed that AOO at room temperature had no obvious influences on the functional groups, but AOO at higher temperatures had a significant effect on the functional groups. The FT-IR spectra of all the samples exhibited a broad absorption band between $3800 \mathrm{~cm}^{-1}$ and $3200 \mathrm{~cm}^{-1}$ due to $-\mathrm{OH}$ and $-\mathrm{NH}$ groups. ${ }^{35}$ The bands at $c a .2925 \mathrm{~cm}^{-1}$ and $2848 \mathrm{~cm}^{-1}$ were attributed to the cycloalkanes or aliphatic $-\mathrm{CH}_{3}$ and $-\mathrm{CH}_{2}$ asymmetric and

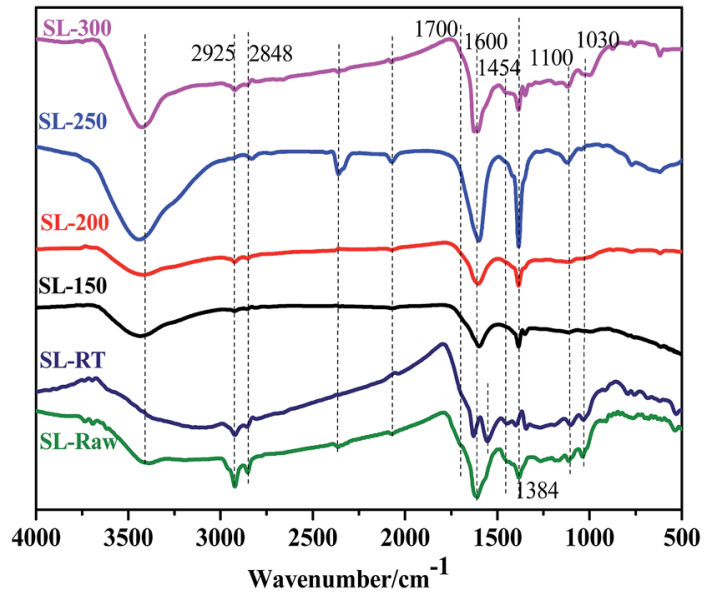

Fig. 4 FT-IR spectra of the coal samples. symmetric stretching vibration. ${ }^{45}$ After the $\mathrm{AOO}$ at different temperatures $\left(150-300{ }^{\circ} \mathrm{C}\right)$, the absorption peak of $2925 \mathrm{~cm}^{-1}$, $2848 \mathrm{~cm}^{-1}$ decreased. Especially, the peak was almost disappeared for the samples of SL-150 and SL-200. When the temperature of AOO treatment rised to $250-300{ }^{\circ} \mathrm{C}$, the absorption peak of $2925 \mathrm{~cm}^{-1}$ and $2848 \mathrm{~cm}^{-1}$ appeared again. The results showed that the content of aliphatic side chain was reduced by $\mathrm{AOO}$, and it came to the lowest value for the samples of the SL-150 and SL-200. The band at ca. $1700 \mathrm{~cm}^{-1}$ was attributed to the carbonyl $(\mathrm{C}=\mathrm{O})$ stretching vibration, and it was generally believed that the absorption was caused by -COOH. ${ }^{46}$ The weak absorption peak can be seen in SL-Raw and SL-RT coal samples. And the peaks were almost invisible for the AOO coal samples at higher temperatures. It was found that the humic acids and other carboxyl compounds in coal could be removed by AOO treatment at high temperatures. ${ }^{47}$ The broad absorption band around $1600 \mathrm{~cm}^{-1}$ and $1580 \mathrm{~cm}^{-1}$ could be assigned to the stretching vibration of $\mathrm{C}=\mathrm{C}$ bonds in aromatic structure. ${ }^{48}$ The deformation vibration of $\mathrm{C}-\mathrm{H}$ in aliphatic hydrocarbon at $1454 \mathrm{~cm}^{-1}$ disappeared with AOO treatment at 150-200 ${ }^{\circ} \mathrm{C}$. The SL-Raw coals exhibited prominent bands in the $1030 \mathrm{~cm}^{-1}$ and $1100 \mathrm{~cm}^{-1}$ region due to $\mathrm{Si}-\mathrm{O}-\mathrm{Si}$ and $\mathrm{Si}-\mathrm{O}-\mathrm{C}$ stretching vibration. ${ }^{49}$ After AOO treatment at room temperature, the peak had no obvious change. However, the two peaks were weakened in the coal samples of AOO at $150-200{ }^{\circ} \mathrm{C}$, but appeared again in the AOO coal samples at $250-300{ }^{\circ} \mathrm{C}$. It showed that the AOO coal samples at room temperature had little effect on the $\mathrm{SiO}_{2}$ in minerals. When the temperature of AOO was improved to $150-200{ }^{\circ} \mathrm{C}$, the peaks at $1100 \mathrm{~cm}^{-1}$ and $1030 \mathrm{~cm}^{-1}$ corresponding to $\mathrm{SiO}_{2}$ were weakened, which may result from the reaction between $\mathrm{SiO}_{2}$ and $\mathrm{NaOH}$ to generate $\mathrm{Na}_{2} \mathrm{SiO}_{3}$. When the temperature rose to $250-300{ }^{\circ} \mathrm{C}$, the sodium silicate hydrolysis reaction maybe occur $\left(\mathrm{Na}_{2} \mathrm{SiO}_{3}+2 \mathrm{H}_{2} \mathrm{O}=\right.$ $\mathrm{H}_{2} \mathrm{SiO}_{3}+2 \mathrm{NaOH}$ ), and $\mathrm{H}_{2} \mathrm{SiO}_{3}$ decomposed into $\mathrm{SiO}_{2}$ (JCPDS 821574) and $\mathrm{H}_{2} \mathrm{O}$ when being heated. Thus the absorption peak of $\mathrm{SiO}_{2}\left(2 \theta=24.23^{\circ}\right.$, JCPDS 82-1574) appeared in the AOO coal sample at $250-300{ }^{\circ} \mathrm{C}$. The above results show that the benzene ring skeleton structure had no obvious change, but the content of the aliphatic side chains on aromatic nucleus and carboxyl groups decreased after $\mathrm{AOO}$ at different temperatures. When the temperatures of AOO fell into the range of $150-200{ }^{\circ} \mathrm{C}$, the 
content of the aliphatic side chains decreased to the lowest level, and the carboxyl groups nearly disappeared, which proved further that the components with high reactivity decreased for the samples treated by $\mathrm{AOO}$ among $150-200{ }^{\circ} \mathrm{C}$.

\subsection{X-ray photoelectron spectroscopy}

X-ray photoelectron spectroscopy (XPS) is an important tool to analyze the coal structure and has been widely used to investigate the surface structure of coal. ${ }^{50-53}$ Fig. 5 shows the XPS C1s spectra of SL-Raw and AOO samples treated at different temperatures. In order to obtain better insight into the effects of AOO on the coal samples, curve fitting was performed using XPSPEAK4.1 software. The C1s spectra demonstrated the presence of five carbon species on the surface of coal samples, which were aromatic units with their alkyl substituent groups (C-C/C$\mathrm{H}, 284.6 \mathrm{eV})$, vacancy defects on functional groups $\left(\mathrm{C}^{*}-\mathrm{C}^{*}\right.$, $285.3 \mathrm{eV}$ ), hydroxyl or ether group (C-O-, $286.3 \mathrm{eV})$, carbonyl $(\mathrm{C}=\mathrm{O}, 287.6 \mathrm{eV})$, and carboxyl $(\mathrm{COO}-, 289.1 \mathrm{eV})$, respectively. ${ }^{30,31,54,55}$ Table 4 summarized the relative amounts of different $\mathrm{C}$ species on lignite surface.

The dominant component of all the samples studied was the carbon in $\mathrm{C}-\mathrm{C}$ and $\mathrm{C}-\mathrm{H}$ bonds. The contents of $\mathrm{C}-\mathrm{C} / \mathrm{C}-\mathrm{H}$ had no obvious change after AOO, indicating that the AOO treatment did not alter the coal surface structure of benzene ring. However, the content of vacancy defect $\mathrm{C}^{*} \mathrm{C}^{*}$ decreased. The lowest amount of such groups was observed in the AOO coal samples treated at $150-200{ }^{\circ} \mathrm{C}$, which was consistent with the results of Raman. The contents of $\mathrm{C}-\mathrm{O}-$ in samples treated by AOO were higher than that of SL-Raw, indicating that the cycloalkanes or aliphatic $-\mathrm{CH}_{3}$ and $-\mathrm{CH}_{2}$ side chain was oxidized due to $\mathrm{AOO}$ treatment. The content of $\mathrm{COO}-$ decreased after AOO treatment, especially for the coal samples SL-150 and SL-200, which may be attributed to the removal of humic acids and other acids from the coal samples in the process of AOO. XPS results further revealed that the benzene skeleton structures on the surface of coal samples had no obvious change after $\mathrm{AOO}$ at different temperatures. The samples treated by AOO within the temperature range of $150-200{ }^{\circ} \mathrm{C}$ gave the lowest content of carboxyl groups, while the content of $\mathrm{C}-\mathrm{O}$ structure with better stability was relatively higher than that of other samples.
Table 4 Relative contents of different C species in C1s from XPS spectra

\begin{tabular}{|c|c|c|c|c|c|c|c|}
\hline \multirow[b]{2}{*}{$E / \mathrm{eV}$} & \multirow{2}{*}{$\begin{array}{l}\text { Carbon } \\
\text { form }\end{array}$} & \multicolumn{6}{|c|}{ Content $/ \%$} \\
\hline & & SL-Raw & SL-RT & SL-150 & SL-200 & SL-250 & SL-300 \\
\hline 284.6 & $\mathrm{C}-\mathrm{C} / \mathrm{C}-\mathrm{H}$ & 75.51 & 75.82 & 77.20 & 77.25 & 76.16 & 76.39 \\
\hline 285.3 & $\mathrm{C}^{*}-\mathrm{C}^{*}$ & 11.60 & 10.82 & 9.86 & 9.71 & 10.57 & 10.40 \\
\hline 286.3 & $\mathrm{C}-\mathrm{O}$ & 5.70 & 6.44 & 7.29 & 7.40 & 7.00 & 7.07 \\
\hline 287.6 & $\mathrm{C}=\mathrm{O}$ & 3.41 & 3.26 & 3.05 & 2.95 & 3.19 & 3.13 \\
\hline 289.1 & COO- & 3.78 & 3.66 & 2.60 & 2.69 & 3.08 & 3.01 \\
\hline
\end{tabular}

\subsection{Combustion reaction performance}

Fig. 6 shows the comparison of the results the fixed bed combustion and thermogravimetric analysis of SL-Raw and AOO samples at different temperatures. As shown in Fig. 6(a), when the raw coal was burned in the air, a large amount of $\mathrm{CO}_{2}$ generated at about $340^{\circ} \mathrm{C}$. The temperature had different effects on combustion reaction parameters of coal samples. The temperatures of $\mathrm{CO}_{2}$ release appeared at $200{ }^{\circ} \mathrm{C}$ and $640{ }^{\circ} \mathrm{C}$ for SL-RT, and the peak intensity of the $640{ }^{\circ} \mathrm{C}$ was much greater than that of $200{ }^{\circ} \mathrm{C}$ peak, which indicated that the $\mathrm{CO}_{2}$ was mainly generated at about $640{ }^{\circ} \mathrm{C}$ of SL-RT. The temperatures of $\mathrm{CO}_{2}$ release moved to the higher temperature range of 760$770{ }^{\circ} \mathrm{C}$ when the $\mathrm{AOO}$ was conducted within the temperature range of $150-200{ }^{\circ} \mathrm{C}$, and there were only one $\mathrm{CO}_{2}$ generation peak. When the $\mathrm{AOO}$ temperature was increased to $250-300{ }^{\circ} \mathrm{C}$, the temperatures of $\mathrm{CO}_{2}$ release was decreased, and there were three $\mathrm{CO}_{2}$ generation peaks. The above experimental results showed that the temperature of the coal sample combustion to generate $\mathrm{CO}_{2}$ increased after the $\mathrm{AOO}$ treatment. The experimental results showed that $\mathrm{AOO}$ had an inerting or inhibiting effect on the combustion of lignite, and the inerting extent varied with the temperatures of $\mathrm{AOO}$. With the $\mathrm{AOO}$ temperature ranging from room temperature to $200{ }^{\circ} \mathrm{C}$, the inerting effect of lignite increased obviously. But when the AOO temperature increased to $250{ }^{\circ} \mathrm{C}$, the inerting effect became weaker.

TG curves in Fig. 6(b) showed that the weight loss for all coal samples mainly appeared at $300{ }^{\circ} \mathrm{C}$, and the weight loss rate of raw coal was higher than that of other AOO samples. All the AOO treatment at different temperatures could slow down the weight loss rate of coal samples, and there were two obvious
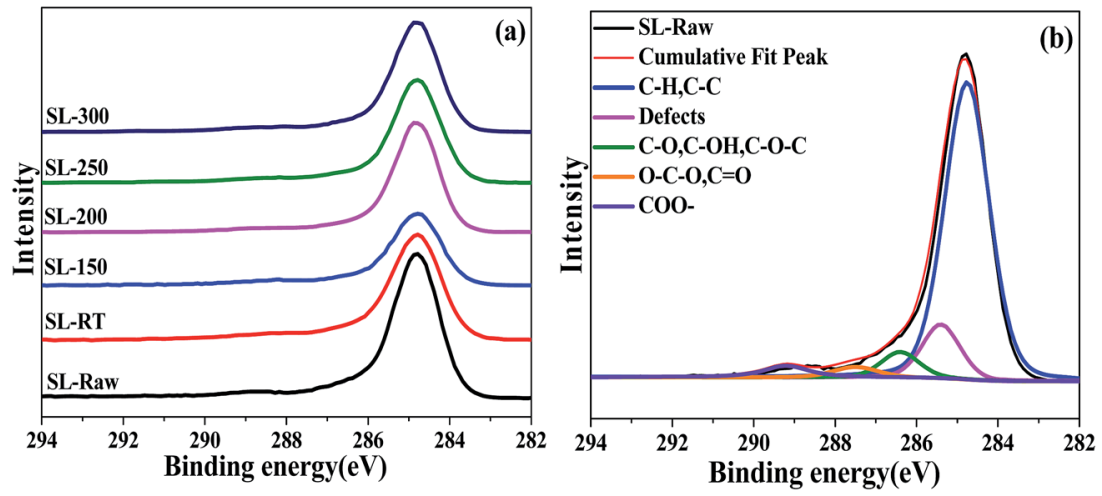

Fig. 5 XPS spectra of C1s peaks of the coal samples and the fitting curves of SL-Raw (a) experimental; (b) fitting. 

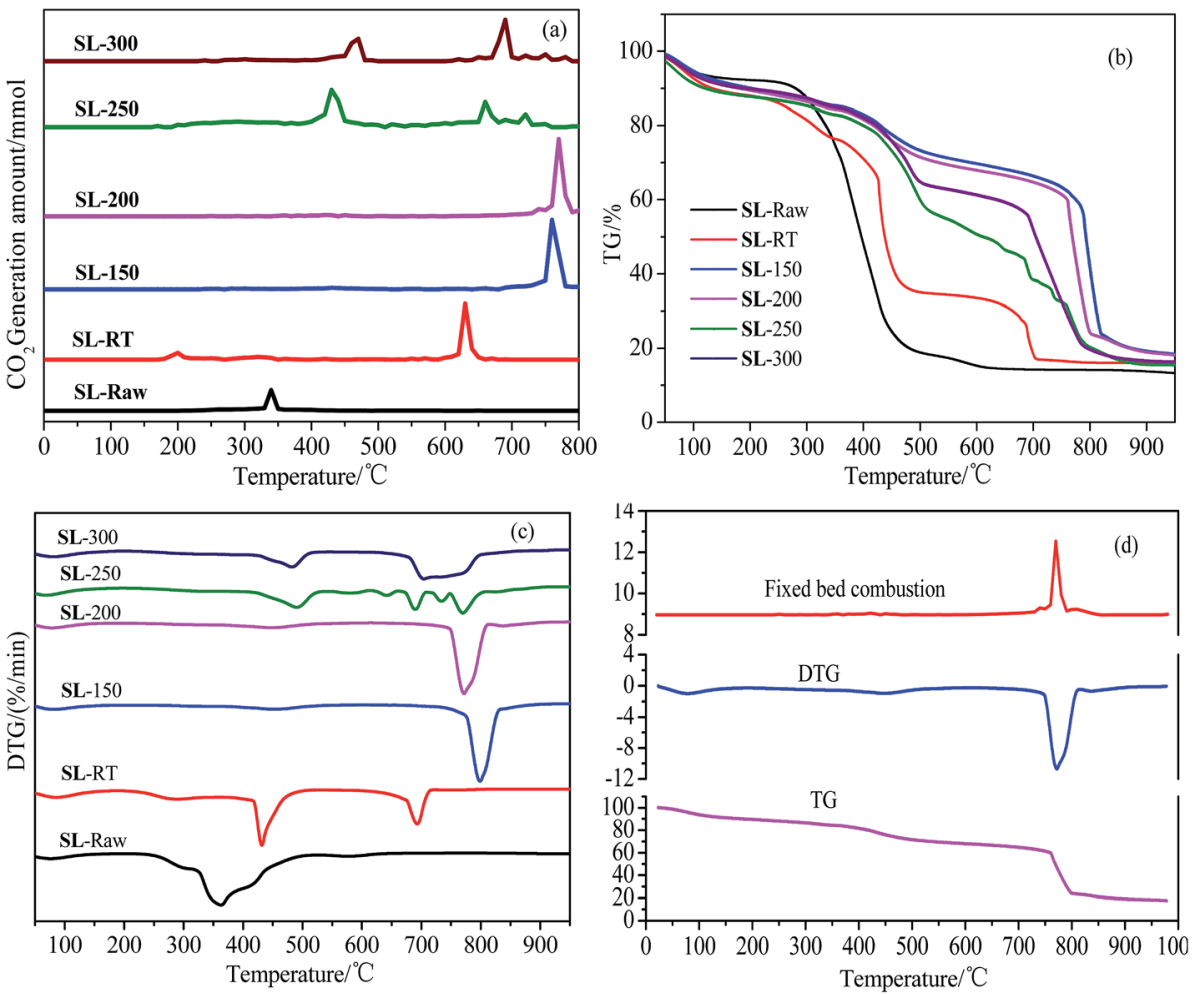

Fig. 6 Comparison of the results of fixed bed combustion and thermogravimetric analysis of coal samples (a) fixed bed combustion curve; (b) TG curve; (c) DTG curve; (d) fixed bed combustion curve, DTG, and TG of SL-200 sample.

weight loss processes for AOO coal samples in range of 400$500{ }^{\circ} \mathrm{C}$ and $700-800{ }^{\circ} \mathrm{C}$, respectively. When $\mathrm{AOO}$ was conducted within the temperature range of $150-200{ }^{\circ} \mathrm{C}$, the samples obtained gave the slowest rate of weight loss before $750^{\circ} \mathrm{C}$, and the main combustion peak moved to the high temperature range (Fig. 6(c)), existing a hysteresis on combustion. These results indicated that the $\mathrm{AOO}$ treatment within the temperature range of $150-200{ }^{\circ} \mathrm{C}$ could definitely decrease chemical oxidation reactivity of the coal samples, resulting in the increasing of combustion temperatures and decreasing in spontaneous combustion tendency. Fig. 6(d) showed that the experimental results on combustion in fixed bed were consistent with those of thermogravimetric analysis.

The ignition temperature can evaluate the spontaneous combustion tendency of the coal samples directly. Therefore, the ignition temperature of different coal samples were calculated using TG-DTG method. ${ }^{2,56}$ The ignition temperature of raw coal was $310{ }^{\circ} \mathrm{C}$, and the value increased to $406{ }^{\circ} \mathrm{C}$ for SL-RT sample. The ignition temperature of AOO samples moved from $310{ }^{\circ} \mathrm{C}$ for raw coal to $740-760{ }^{\circ} \mathrm{C}$ when the $\mathrm{AOO}$ was conducted within the range of $150-200{ }^{\circ} \mathrm{C}$. When the AOO temperatures fell into the range of $250-300{ }^{\circ} \mathrm{C}$, the ignition temperature decreased to $410-440{ }^{\circ} \mathrm{C}$, which was still higher than that of raw coal and SL-RT.

\section{Conclusion}

The effects of AOO temperature on the microcrystalline structure and combustion properties of coal samples were comprehensively investigated. After the AOO pretreatment, the benzene ring skeleton structures in lignite had no obvious changes. However, the amounts of aliphatic side chains on aromatic nucleus and the content of carbonyl functional groups decreased. The size of the aromatic layer and the degree of order increased. The effect was more obvious when the AOO temperature fell the range of $150-200{ }^{\circ} \mathrm{C}$. The combustion reaction results indicated that the ignition temperatures of the samples treated by $\mathrm{AOO}$ at room temperature was increased from $310{ }^{\circ} \mathrm{C}$ (SL-Raw) to $406{ }^{\circ} \mathrm{C}$ (SL-RT). Thus AOO had an inerting effect on the combustion of lignite. The inerting effect of AOO was more obvious when the temperature of AOO fell into $150-200{ }^{\circ} \mathrm{C}$, for which the ignition temperature greatly increased from $310{ }^{\circ} \mathrm{C}$ (SL-Raw) to $740-760{ }^{\circ} \mathrm{C}$. Further increasing the $\mathrm{AOO}$ temperatures to $250-300{ }^{\circ} \mathrm{C}$, the ignition temperature of the samples decreased $\left(410-440{ }^{\circ} \mathrm{C}\right)$, which was still higher than that of SL-Raw and SL-RT. Therefore, AOO at improved temperatures $\left(150-200^{\circ} \mathrm{C}\right)$ could effectively enhanced the ignition temperature of lignite, and thus inhibit their spontaneous combustion tendency, which may be beneficial for the utilization of lignite in industry.

\section{Acknowledgements}

The authors greatly acknowledge the financial support from the National Natural Science Foundation of China (21566028, 21566029, 21676149, 21606134), the Incentive Fund for the Scientific and Technology Innovation Program of Inner Mongolia, the Major Basic Research Open Programs of Inner 
Mongolia, the Natural Science Foundation of Inner Mongolia (2014MS0220, 2016BS0204).

\section{References}

1 X. C. Liu, T. Hirajima, M. Nonaka and K. Sasaki, Ind. Eng. Chem. Res., 2015, 54, 8971-8978.

2 J. Tanner and S. Bhattacharya, Chem. Eng. J., 2016, 285, 331340.

3 M. Yilgin, N. D. Duranay and D. Pehlivan, Energy Convers. Manage., 2010, 51, 1060-1064.

4 Q. Ji, S. Tabassum, G. Yu, C. Chu and Z. Zhang, RSC Adv., 2015, 5, 40402-40413.

5 A. Cuadrat, A. Abad, F. García-Labiano, P. Gayán, L. F. de Diego and J. Adánez, Chem. Eng. J., 2012, 195, 91-102.

6 M. Z. Khan, D. H. Chun, J. Yoo, D. K. Sang, Y. J. Rhim, H. K. Choi, J. Lim, S. Lee and A. Rifella, $R S C A d v .$, 2015, 5, 63955-63963.

7 A. Tahmasebi, J. L. Yu, Y. N. Han, F. K. Yin, S. Bhattacharya and D. Stokie, Energy Fuels, 2012, 26, 3651-3660.

8 M. Wang, X. Fan, X. Y. Wei, J. P. Cao, Y. P. Zhao, S. Z. Wang, C. F. Wang and R. Y. Wang, Fuel, 2016, 183, 115-122.

9 B. K. Saikia, R. K. Boruah and P. K. Gogoi, J. Earth Syst. Sci., 2007, 116, 575-579.

10 A. O. Odeh, Energy Fuels, 2015, 29, 2676-2684.

11 J. A. Orrego-Ruiz, R. Cabanzo and E. Mejía-Ospino, Int. J. Coal Geol., 2011, 85, 307-310.

12 Z. L. Song, L. S. Yao, C. M. Jing, X. Q. Zhao, W. L. Wang, J. Sun, Y. P. Mao and C. Y. Ma, Ind. Eng. Chem. Res., 2016, 55, 3167-3176.

13 K. Baris, S. Kizgut and V. Didari, Fuel, 2012, 93, 423-432.

14 Y. M. Song, W. Feng, N. Li, Y. Li, K. D. Zhi, Y. Y. Teng, R. X. He, H. C. Zhou and Q. S. Liu, Fuel, 2016, 183, 659-667.

15 J. Peuravuori, A. J. Simpson, B. Lam, P. Žbánková and K. Pihlaja, J. Mol. Struct., 2007, 826, 131-142.

16 H. H. Wang, B. Z. Dlugogorski and E. M. Kennedy, Fuel, 2001, 81, 1913-1923.

17 H. H. Wang, B. Z. Dlugogorski and E. M. Kennedy, Prog. Energy Combust. Sci., 2003, 29, 487-513.

18 Y. Fei, A. A. Aziz, S. Nasir, W. R. Jackson, M. Marshall, J. Hulston and A. L. Chaffee, Fuel, 2009, 88, 1650-1655.

19 S. Mukherjee and P. C. Borthakur, Fuel Process. Technol., 2004, 85, 93-101.

20 S. Nasir, T. B. Sarfaraz, T. V. Verheyen and A. L. Chaffee, Fuel Process. Technol., 2011, 92, 983-991.

21 N. Wijaya and L. A. Zhang, Energy Fuels, 2011, 25, 1-16.

22 X. C. Liu, F. Li, L. L. Song, X. H. Wang and Y. Zhang, Int. J. Min. Sci. Technol., 2014, 24, 51-55.

23 L. Feng, X. C. Liu, L. L. Song, X. H. Wang, Y. Zhang, T. W. Cui and H. Y. Tang, Powder Technol., 2013, 247, 19-23.

24 M. Çulfaz, M. Ahmed and S. Gürkan, Fuel Process. Technol., 1996, 47, 99-109.

25 W. H. Wang, Y. C. Hou, W. Z Wu, M. G. Niu and T. Wu, Ind. Eng. Chem. Res., 2013, 52, 680-685.

26 W. H. Wang, Y. C. Hou, W. Z. Wu, M. G. Niu and T. Wu, Ind. Eng. Chem. Res., 2012, 51, 14994-15003.
27 W. H. Wang, Y. C. Hou, W. Z. Wu and M. G. Niu, Fuel Process. Technol., 2013, 112, 7-11.

28 W. H. Wang, Y. C. Hou, M. G. Niu, T. Wu and W. Z. Wu, Fuel Process. Technol., 2013, 110, 184-189.

29 P. S. Li, Y. Hu, W. Yu, Y. N. Yue, Q. Xu, S. Hu, N. S. Hu and J. Yang, J. Hazard. Mater., 2009, 167, 1126-1132.

30 M. Kozlowski, Fuel, 2004, 83, 259-265.

31 T. Grzybeka, R. Pietrzakb and H. Wachowska, Fuel Process. Technol., 2002, 77, 1-7.

32 H. Takagi, K. Maruyama, N. Yoshizaw, Y. Yamada and Y. Sato, Fuel, 2004, 83, 2427-2433.

33 H. L. Lin, K. J. Li, X. W. Zhang and H. X. Wang, Energy Fuels, 2016, 30, 3809-3814.

34 A. D. Machado, A. S. Mexias, A. C. F. Vilela and E. Osorio, Fuel, 2013, 114, 224-228.

35 O. O. Sonibare, T. Haeger and S. F. Foley, Energy, 2010, 35, 5347-5353.

36 X. J. Qi, X. Guo, L. C. Xue and C. G. Zheng, J. Anal. Appl. Pyrolysis, 2014, 110, 401-407.

37 L. M. Lu, V. Sahajwalla and D. Harris, Energy Fuels, 2000, 14, 869-876.

38 A. Sadezky, H. Muckenhuber, H. Grothe, R. Niessner and U. PÖschl, Carbon, 2005, 43, 1731-1742.

39 A. Guedes, B. Valentim, A. C. Prieto and F. Noronha, Fuel, 2012, 97, 443-449.

40 S. Q. Wang, H. F. Cheng, D. Jiang, F. Huang, S. Su and H. P. Bai, Spectrochim. Acta, Part A, 2014, 132, 767-770.

41 A. C. Ferrari, Solid State Commun., 2007, 143, 47-57.

42 F. J. Wang, S. Zhang, Z. D. Chen, C. Liu and Y. G. Wang, J. Anal. Appl. Pyrolysis, 2014, 105, 269-275.

43 A. Zaida, E. Bar-Ziv, L. R. Radovic and Y. J. Lee, Proc. Combust. Inst., 2007, 31, 1881-1887.

44 Y. Li, H. P. Yang, J. H. Hu, X. H. Wang and H. P. Chen, Fuel, 2014, 117, 1174-1180.

45 Y. Lin, D. Wang and T. Wang, Chem. Eng. J., 2012, 191, 31-37.

46 Y. Ohtsuka and K. M. Asami, Energy Fuels, 1996, 10, 431435.

47 J. Hayashi, S. Aizawa, H. Kumagai and T. Chiba, Energy Fuels, 1999, 13, 69-76.

48 X. L. Shang, K. Hou, J. J. Wu, Y. X. Zhang, J. Q. Liu and J. Qi, Fuel, 2016, 182, 749-753.

49 Q. S. Wu and S. P. Li, J. Wuhan Univ. Technol., Mater. Sci. Ed., 2011, 26, 514-518.

50 H. Estrade-Szwarckopf, Carbon, 2004, 42, 1713-1721.

51 B. Wang, Y. J. Peng and S. Vink, Energy Fuels, 2013, 27, 48694874.

52 Y. Hu, P. Li and N. Hu, Data Sci. J., 2007, 6, S317-S323.

53 W. C. Xia, J. G. Yang and C. Liang, Appl. Surf. Sci., 2014, 293, 293-298.

54 Y. Yamada, H. Yasuda, K. Murota, M. Nakamura, T. Sodesawa and S. Sato, J. Mater. Sci., 2013, 48, 8171-8198.

55 S. R. Kelemen, M. Afeworki, M. L. Gorbaty and A. D. Cohen, Energy Fuels, 2002, 16, 1450-1462.

56 X. Y. Huang, X. M. Jiang, X. X. Han and H. Wang, Energy Fuels, 2008, 22, 3756-3762. 